\title{
METABOLIC SYNDROME IN PSORIASIS PATIENTS: A COMPARATIVE STUDY
}

\author{
K. Venkata Chalam ${ }^{1}$, C. Subhashini², Rashmi Naldeega 3 , G. Suryanaraya4, Revathi V5, Padma Sri S6, Rajesh Kumar7, \\ P. Anila Sunandini Nayar ${ }^{8}$
}

${ }^{1}$ Assistant Professor, Department of Dermatology, Venereology and Leprosy, Andhra Medical College, Visakhapatnam. ${ }^{2}$ Assistant Professor, Department of Dermatology, Venereology and Leprosy, Andhra Medical College, Visakhapatnam. 3 Junior Resident, Department of Dermatology, Venereology and Leprosy, Andhra Medical College, Visakhapatnam. ${ }^{4}$ Assistant Professor, Department of Dermatology, Venereology and Leprosy, Andhra Medical College, Visakhapatnam. $5 J u n i o r$ Resident, Department of Dermatology, Venereology and Leprosy, Andhra Medical College, Visakhapatnam. 6Junior Resident, Department of Dermatology, Venereology and Leprosy, Andhra Medical College, Visakhapatnam. 7 Junior Resident, Department of Dermatology, Venereology and Leprosy, Andhra Medical College, Visakhapatnam. 8Professor \& HOD, Department of Dermatology, Venereology and Leprosy, Andhra Medical College, Visakhapatnam.

ABSTRACT: The patients with Psoriasis are at increased risk of developing Metabolic Syndrome (MS). Proinflammatory cytokines such as tumor necrosis factor- $\alpha$, interleukin- 6 that are increased in the psoriatic plaques are known to contribute to features of MS such as hypertension, dyslipidemia and insulin resistance.

AIMS: (1) To know the prevalence of MS in patients with psoriasis. (2) To compare the results with control population.

MATERIALS AND METHODS: A hospital based comparative study was conducted involving 60 adult patients with psoriasis and 60 age and sex matched controls. All participants were evaluated for components of MS.

RESULTS: Both groups included 33 males and 27 females. MS was present in 15 out of $60(25 \%)$ patients with psoriasis and 12 out of $60(20 \%)$ controls. Conclusion: Our results suggest that there is a slightly higher prevalence of Metabolic Syndrome in patients with Psoriasis compared to the control population.

KEYWORDS: Comparative Study, Metabolic Syndrome, Psoriasis.

HOW TO CITE THIS ARTICLE: K. Venkata Chalam, C. Subhashini, Rashmi Naldeega, G. Suryanaraya, Revathi V, Padma Sri S, Rajesh Kumar, P. Anila Sunandini Nayar. "Metabolic Syndrome in Psoriasis Patients: A Comparative Study". Journal of Evolution of Medical and Dental Sciences 2015; Vol. 4, Issue 89, November 05; Page: 15443-15446, DOI: 10.14260/jemds/2015/2205.

INTRODUCTION: Psoriasis is a chronic, T-cell mediated inflammatory disease of the skin and occasionally the joints. Several observational studies have recently demonstrated that psoriasis is associated with systemic disorders such as cardiovascular disease, the metabolic syndrome (MS), cancer, chronic obstructive pulmonary disease, inflammatory bowel disease, depression and osteoporosis. ${ }^{1,2}$ The suggested causal link between psoriasis and associated diseases is the presence of systemic inflammation and elevated levels of cytokines such as tumor necrosis factor- $\alpha$ (TNF- $\alpha$ ) and interleukin-6 (IL-6). ${ }^{3}$

There have been recent recommendations to "upgrade" Psoriasis from a cutaneous to a systemic disease, but the topic remains contentious. ${ }^{[2]}$ A term "Psoriasis march" is described where the state of chronic inflammation in the patient affected by psoriasis leads to insulin resistance, which leads to endothelial dysfunction and atherosclerosis, and consequently to myocardial infarction and stroke. 4

MS, defined as a cluster of risk factors including central obesity, atherogenic dyslipidemia, hypertension and glucose intolerance, is a strong predictor of cardiovascular disease,

Financial or Other, Competing Interest: None

Submission 14-10-2015, Peer Review 15-10-2015,

Acceptance 23-10-2015, Published 04-11-2015.

Corresponding Author:

Dr. K. Venkata Chalam

Assistant Professor,

Department of DVL

Andhra Medical College, KGH, Visakhapatnam.

E-mail: dvlkgh2015@gmail.com

DOI: 10.14260/jemds/2015/2205. that confers a cardiovascular risk higher than the individual components.5,6 Increased mortality from cardiovascular disease in patients with severe psoriasis has been documented and psoriasis may be an independent risk factor for myocardial infarction, especially in young patients. ${ }^{6}$ Psoriasis is associated with MS, independent of its severity. ${ }^{6}$

Several factors may contribute to an unfavorable cardiovascular risk profile in patients with psoriasis, such as cigarette smoking, alcohol consumption, obesity, physical inactivity, homocysteinemia, psychological stress, and depression, all of which are more prevalent in patients with psoriasis.[7,2]

In addition, many traditional systemic therapies for psoriasis may also worsen cardiovascular risk factors such as hyperlipidemia, hypertension and homocysteinemia.[7,2] Psoriasis affects about 3\% of the population world-wide.[7] Recent studies have estimated prevalence of MS to be $15-24 \%$ in the general population and $30-50 \%$ among psoriasis patients. This increased frequency imposes a substantial burden on the overall health of psoriasis patients, which needs to be appropriately addressed during treatment of such patients.

AIMS:

1. To know the prevalence of MS in patients with psoriasis.

2. To compare the results with control population.

MATERIALS AND METHODS: This was a hospital based comparative study. During the study period from August 2014 to September 2015, 60 psoriasis patients attending the Dermatology Department are enrolled after obtaining informed consent and 60 age and sex matched healthy controls were enrolled after obtaining informed consent. 
Cases: A total of 60 patients with psoriasis satisfying the following inclusion and exclusion criteria were enrolled:

Inclusion criteria: Patients with psoriasis, 18-45 years of age and those with psoriasis of at least 6 months duration.

Exclusion criteria: Patients with psoriasis $<18$ years of age and $>45$ years, those with psoriasis of $<6$ months duration and those on systemic treatment for psoriasis, those diagnosed with diabetes mellitus, hypertension and dyslipidemia.

Controls: 60 age and sex matched controls satisfying the inclusion and exclusion criteria were enrolled.

- Inclusion criteria: Healthy individuals of 18-45 years age.

- Exclusion criteria: Diagnosed cases of diabetes mellitus, hypertension and dyslipidemia.

After obtaining informed consent from the patients, relevant data such as age, sex, occupation, age at the onset of psoriasis, psoriasis area severity index (PASI), presence of psoriatic arthropathy and psoriatic erythroderma were collected in a proforma. PASI was calculated as given below.[7] Four sites of affection, the head $(\mathrm{h})$, upper limb $(\mathrm{u})$, trunk $(\mathrm{t})$ and lower limbs (1), were separately scored by using three parameters, erythema (E), infiltration (I) and desquamation (D), each of which was graded on a severity scale of $0-4$, where $0=$ nil, $1=$ mild, $2=$ =moderate, $3=$ severe and $4=$ =very severe.

The area-wise percentage involvement of the involved sites was calculated as: $1 \leq 10 \%$ area; $2=10-29 \%$; $3=30-49 \%$; $4=50-69 \%$; $5=70-89 \%$; and $6=$ more than $90 \%$. The final formula for PASI score: PASI $=0.1 \quad(\mathrm{Eh}+\mathrm{Ih}+\mathrm{Dh}) \quad \mathrm{Ah}+0.2$ $(\mathrm{Eu}+\mathrm{Iu}+\mathrm{Du}) \mathrm{Au}+0.3(\mathrm{Et}+\mathrm{It}+\mathrm{Dt}) \mathrm{At+0.4}(\mathrm{El}+\mathrm{Il}+\mathrm{Dl}) \mathrm{A} 1$.

For MS, following parameters were assessed: waist circumference, triglyceride level, high density lipoprotein (HDL) cholesterol level, blood pressure and fasting glucose. To determine the waist circumference, measuring tape was placed around the abdomen at the level of uppermost part of the pelvic bone, while ensuring that the tape measure remained horizontal and was snug without causing compression on the skin. Venous blood samples were collected from the patients after they fasted overnight (at least 8h).

Triglycerides and serum cholesterol were measured using standard enzymatic procedure. Blood pressure was recorded in a sitting posture and was calculated as an average of two measurements after the patients took the rest for 5 min. MS was diagnosed if three or more criteria of the National Cholesterol Education Program's Adult Treatment Panel III (ATP-III) were present, as given below: ${ }^{[8\}}$ NCEP: ATP III 2001.

\section{Three or more of the following:}

1. Central obesity: Waist circumference $>102 \mathrm{~cm} \mathrm{(M),}>88$ $\mathrm{cm}(\mathrm{F})$.

2. Hypertriglyceridemia: Triglycerides $>/=150 \mathrm{mg} / \mathrm{dL}$ or specific medication.

3. Low HDL cholesterol: $<40 \mathrm{mg} / \mathrm{dL}(\mathrm{M})$ and $<50 \mathrm{mg} / \mathrm{dL}$ (F), respectively, or specific medication.

4. Hypertension: Blood pressure $>/=130 \mathrm{~mm}$ systolic or $>$ /=85 mm diastolic or specific medication.
5. Fasting plasma glucose: $>/=100 \mathrm{mg} / \mathrm{dL}$ or specific medication or previously diagnosed Type 2 diabetes.

Ethics committee clearance was obtained prior to the study.

RESULTS: Age of the 60 cases and controls, 33 each were male and 27 female. The mean age of cases was 34.75. The mean age of the controls was 34.75. Psoriasis cases with MS had a mean age of 39.66 while controls with MS had a mean age of 41.25 .

Type of psoriasis of the 60 cases, 51 had psoriasis vulgaris, 2 had guttate psoriasis, 1 had psoriatic erythroderma, 1 had acute generalized pustular psoriasis and 5 patients had palmoplantar psoriasis.

PASI: The mean PASI among cases was 8.63. The mean PASI among psoriasis patients with MS was 9.14 and in those without MS was 8.46.

Body Mass Index (BMI): The mean BMI among case was 23.19 and in controls was 22.61. The mean BMI among cases with MS was 39.66 and among controls with MS was 45 .

Abdominal Obesity: $16.66 \%$ of cases had abdominal obesity and $11.66 \%$ of controls had abdominal obesity. $33.33 \%$ of cases with MS had abdominal obesity and $33.33 \%$ of controls with MS had abdominal obesity.

Fasting blood sugar, S. Triglycerides and S. HDL: The mean FBS among cases was $93.08 \mathrm{mg} / \mathrm{dl}$ and among cases was $95.1 \mathrm{mg} / \mathrm{dl}$. The mean FBS among cases with MS was $126.4 \mathrm{mg} / \mathrm{dl}$ and amomg controls with MS was $143.33 \mathrm{mg} / \mathrm{dl}$.

The mean S. triglycerides among cases was $130.9 \mathrm{mg} / \mathrm{dl}$ and among controls was $136.7 \mathrm{mg} / \mathrm{dl}$. The mean S. Triglycerides among cases with MS was $186.8 \mathrm{mg} / \mathrm{dl}$ and among controls with MS was $181 \mathrm{mg} / \mathrm{dl}$. The mean S. HDL among cases was $34.75 \mathrm{mg} / \mathrm{dl}$ and among controls was $46.31 \mathrm{mg} / \mathrm{dl}$. The mean S.HDL among cases with MS was $29.66 \mathrm{mg} / \mathrm{dl}$ and among controls with MS was $32.74 \mathrm{mg} / \mathrm{dl}$.

Systolic and Diastolic Blood Pressure: The mean Systolic Blood Pressure among cases was $120.93 \mathrm{~mm}$ of hg and among controls was $121.83 \mathrm{~mm}$ of hg. The mean Systolic Blood Pressure among cases with MS was $129.33 \mathrm{~mm}$ of hg and among controls with MS was $131.66 \mathrm{~mm}$ of hg.

The mean Diastolic Blood Pressure among cases was $81 \mathrm{~mm}$ of hg and among controls was $79.83 \mathrm{~mm}$ of hg. The mean Diastolic Blood Pressure among cases with MS was $88.66 \mathrm{~mm}$ of hg and among controls with MS was $88.33 \mathrm{~mm}$ of hg.

MS in cases and controls $25 \%$ of cases had MS and $20 \%$ of controls had MS. Out of 60 cases 15 had MS, 9(15\%) were male and $6(10 \%)$ were female while 12 out of 60 controls had MS, $7(11.66 \%)$ were male and $5(8.33 \%)$ were female.

DISCUSSION: Our study observed a higher prevalence of MS in cases (25\%) compared to controls (20\%) as per NCEP ATP III criteria. Mebazaa et al., ${ }^{9}$ studied 164 psoriasis patients and 216 controls and showed a higher prevalence of MS in psoriatic patients (35.5\%) compared to controls (30.8\%). Cases and control groups with MS in our study had higher mean age compared to those without MS in their respective groups. Sumner et al., ${ }^{10}$ also concluded that the prevalence of MS increased with age, prevalence being $6.6 \%$ in young adults and $34 \%$ in older adults. MS was independent of PASI in our study. Similar results were observed in studies performed by Gisondi et al.[6] and Nisa and Qazi. ${ }^{11}$ 
We found that mean BMI, Waist circumference, Systolic blood pressure, Diastolic blood pressure, fasting blood sugar level, S. Total cholesterol, S. Triglycerides, S. LDL, S. VLDL were higher in psoriasis patients with MS compared to those without MS while mean S. HDL was low in cases with MS compared to cases without MS. Dreiher et al.,12 found a significant increase in lipid levels among cases than in controls $(\mathrm{P}<0.001)$. Shapiro et 13 al., found that psoriasis was associated hyperlipidemia, but was not associated with an increase in LDL level. Cohen et al., ${ }^{14}$ have found that psoriasis is associated with dyslipidemia $(\mathrm{P}<0.015)$.

CONCLUSION: Our study showed a higher prevalence of Metabolic Syndrome among patients with Psoriasis compared to the control population. The prevalence of MS in cases being $25 \%$ while in controls it was $20 \%$. However, the statistical significance of this difference, the influence of race, type of lifestyle, factors like smoking, drinking and food habbits, socio. economic status and occupations involving heavy work on the occurrence of MS in psoriasis needs to be examined in larger studies.

\section{REFERENCES:}

1. Nijsten T, Wakkee M. Complexity of the association between psoriasis and comorbidities. J Invest Dermatol 2009;129:1601-3.

2. Gottlieb AB, Chao C, Dann F. Psoriasis comorbidities. J Dermatolog Treat 2008;19:5-21.

3. Lakshmi S, Nath AK, Udayashankar C. Metabolic syndrome in patients with psoriasis: A comparative study. Indian Dermatol Online J 2014;5:132-7.

4. Topić I, Šimić D. Prevalence of metabolic syndrome in patients with psoriasis at Mostar Clinical Hospital. Acta Clin Croat. 2013;52(1):53-58.

5. Gulliver W. Long-term prognosis in patients with psoriasis. Br J Dermatol 2008;159 Suppl 2:2-9.

6. Zindancı I, Albayrak O, Kavala M, Kocaturk E, Can B, Sudogan S, et al. Prevalence of metabolic syndrome in patients with psoriasis. Scientific World Journal 2012;2012:312463.
7. Bhor U, Pande S. Scoring systems in dermatology. Indian J Dermatol Venereol Leprol 2006;72:315-21.

8. Grundy SM, Becker D, Clark LT, Cooper RS, Denke MA, Howard WJ,et al. Third Report of the National Cholesterol Education ProgramExport Panel on Detection, Evaluation, and Treatment of High Blood

Cholesterol in Adults (Adult Treatment Panel III). Washington, DC: National Cholesterol Education Program, National Heart, Lung, and Blood Institute; National Institutes of Health; 2002; NIH Publication

No. 02-5215.

http://www.nhlbi.nih.gov/guidelines/cholesterol/ atp3xsum.pdf

9. Mebazaa A, El Asmi M, Zidi W, Zayani Y, Cheikh Rouhou R, El Ounifi S,et al. Metabolic syndrome in Tunisian psoriatic patients: Prevalence and determinants. J Eur Acad Dermatol Venereol 2011;25:705-9.

10. Sumner AD, Sardi GL, Reed JF 3rd. Components of the metabolic syndrome differ between young and old adults in the US population. J Clin Hypertens (Greenwich) 2012;14:502-6.

11. Nisa N, Qazi MA. Prevalence of metabolic syndrome in patients with psoriasis. Indian J Dermatol Venereol Leprol 2010;76:662-5.

12. Dreiher J, Weitzman D, Davidovici B, Shapiro J, Cohen AD. Psoriasis and dyslipidaemia: A population-based study. Acta Derm Venereol2008;88:561-5.

13. Shapiro J, Cohen AD, Weitzman D, Tal R, David M. Psoriasis and cardiovascular risk factors: A case-control study on inpatients comparing psoriasis to dermatitis. J Am Acad Dermatol 2012;66:252-8.

14. Cohen AD, Dreiher J, Shapiro Y, Vidavsky L, Vardy DA, Davidovici B, et al. Psoriasis and diabetes: A populationbased cross-sectional study.J Eur Acad Dermatol Venereol 2008;22:585-9.

\begin{tabular}{|c|c|c|c|c|c|}
\hline $\begin{array}{l}\text { Sl. } \\
\text { No. }\end{array}$ & Parameters & Cases & $\begin{array}{c}\text { Cases } \\
\text { with } \\
\text { MS(15) }\end{array}$ & Controls & $\begin{array}{l}\text { Controls with } \\
\text { MS } \\
\text { (12) }\end{array}$ \\
\hline 1. & 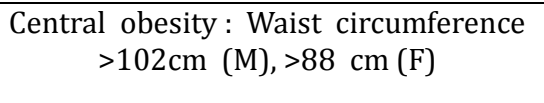 & $\begin{array}{l}16.66 \% \\
(10 / 60)\end{array}$ & $\begin{array}{l}10 \% \\
(6 / 60)\end{array}$ & $\begin{array}{l}11.66 \% \\
(7 / 60)\end{array}$ & $\begin{array}{l}6.66 \% \\
(4 / 60)\end{array}$ \\
\hline 2. & $\begin{array}{l}\text { Hypertriglyceridemia : Triglycerides } \\
>/=150 \mathrm{mg} / \mathrm{dL} \text { or specific medication }\end{array}$ & $\begin{array}{l}31.66 \% \\
(19 / 60)\end{array}$ & $\begin{array}{l}23.33 \% \\
(14 / 60)\end{array}$ & $\begin{array}{c}20 \% \\
(12 / 60)\end{array}$ & $\begin{array}{c}20 \% \\
(12 / 60)\end{array}$ \\
\hline 3. & $\begin{array}{c}\text { Low HDL cholesterol : }<40 \mathrm{mg} / \mathrm{dL}(\mathrm{M}) \\
\text { and }<50 \mathrm{mg} / \mathrm{dL}(\mathrm{F}) \text {, respectively, or } \\
\text { specific medication }\end{array}$ & $\begin{array}{c}80 \% \\
(48 / 60)\end{array}$ & $\begin{array}{l}23.33 \% \\
(14 / 60)\end{array}$ & $\begin{array}{l}26.66 \% \\
(16 / 60)\end{array}$ & $\begin{array}{c}20 \% \\
(12 / 60)\end{array}$ \\
\hline 4. & $\begin{array}{l}\text { Hypertension : Blood pressure } \\
>/=130 \mathrm{~mm} \text { systolic or }>/=85 \mathrm{~mm} \\
\text { diastolic or specific medication }\end{array}$ & $\begin{array}{c}45 \% \\
(27 / 60)\end{array}$ & $\begin{array}{l}21.66 \% \\
(13 / 60)\end{array}$ & $\begin{array}{l}38.33 \% \\
(23 / 60)\end{array}$ & $\begin{array}{l}18.33 \% \\
(11 / 60)\end{array}$ \\
\hline 5. & $\begin{array}{c}\text { Fasting plasma glucose }:>/=100 \\
\text { mg/dL or specific medication or } \\
\text { previously diagnosed Type } 2 \text { diabetes }\end{array}$ & $\begin{array}{l}8.33 \% \\
(5 / 60)\end{array}$ & $\begin{array}{l}6.66 \% \\
(4 / 60)\end{array}$ & $\begin{array}{l}16.66 \% \\
(10 / 60)\end{array}$ & $\begin{array}{l}16.66 \% \\
(10 / 60)\end{array}$ \\
\hline \multicolumn{6}{|c|}{$\begin{array}{l}\text { Table 1: Comparasion of Percentage of cases and controls satisfying } \\
\text { individual parameters of NCEP ATP III criteria for Metabolic Synrome }\end{array}$} \\
\hline
\end{tabular}




\begin{tabular}{|c|c|c|c|}
\hline Sl. No. & & cases & controls \\
\hline 1. & Number & 60 & 60 \\
\hline 2. & Gender & Males:33,Females:27 & Males:33,Females:27 \\
\hline 3. & Age & 34.75 & 34.75 \\
\hline 4. & BMI & 23.19 & 22.61 \\
\hline 5. & Waist circumference & 83.75 & 86 \\
\hline 6. & Systolic BP (mmHg) & 120.93 & 121.83 \\
\hline 7. & Diastolic BP (mmHg) & 81 & 79.83 \\
\hline 8. & Triglyceride (mg/dL) & 130.9 & 136.7 \\
\hline 9. & Total cholesterol (mg/dL) & 154.06 & 130.23 \\
\hline 10. & HDL (mg/dL) & 34.75 & 96.31 \\
\hline 11. & LDL (mg/dL) & 95.99 & 32.23 \\
\hline 12. & VLDL (mg/dL) & 26.25 & 95.1 \\
\hline 13. & FBS (mg/dL) & 93.08 & \\
\hline \multicolumn{3}{|c|}{ Table 2: Average Age, BMI, Waist Circumference, BP, } \\
\hline
\end{tabular}

\begin{tabular}{|c|c|c|c|}
\hline Sl. No. & & With MS & Without MS \\
\hline 1. & Number of patients & 15 & 45 \\
\hline 2. & Age (years) & 39.66 & 33.11 \\
\hline 3. & Gender & Males:9,Females:6 & Males:24,Females:21 \\
\hline 4. & PASI score & 9.14 & 8.46 \\
\hline 5. & BMI (kg/m2) & 25.476 & 22.43 \\
\hline 6. & Waist circumference (cm) & 87.4 & 82.5 \\
\hline 7. & Systolic BP (mm Hg) & 129.33 & 115.73 \\
\hline 8. & Diastolic BP (mm Hg) & 88.66 & 78.44 \\
\hline 9. & Triglyceride (mg/dL) & 186.8 & 112.26 \\
\hline 10. & Total cholesterol (mg/dL) & 162.26 & 151.33 \\
\hline 11. & HDL (mg/dL) & 29.66 & 36.44 \\
\hline 12. & LDL (mg/dL) & 103.66 & 93.44 \\
\hline 13. & VLDL (mg/dL) & 32.6 & 24.13 \\
\hline 14. & FBS (mg/dL) & 126.4 & 81.977 \\
\hline Table 3: Comparative Characteristics of Psoriasis Cases with and without Metabolic Syndrome \\
\hline \multicolumn{4}{|r}{}
\end{tabular}

\begin{tabular}{|c|c|c|c|}
\hline $\begin{array}{c}\text { Sl. } \\
\text { No. }\end{array}$ & & Cases & Controls \\
\hline 1. & Number of individuals & 15 & 12 \\
\hline 2. & Age (years) & 39.66 & 41.25 \\
\hline 3. & Gender & Males:9,Females:6 & Males:7,Females:5 \\
\hline 4. & BMI (kg/m2) & 25.476 & 24.56 \\
\hline 5. & Waist circumference (cm) & 87.4 & 88.99 \\
\hline 6. & Systolic BP (mm Hg) & 129.33 & 131.66 \\
\hline 7. & Diastolic BP (mm Hg) & 88.66 & 88.33 \\
\hline 8. & Triglyceride (mg/dL) & 186.8 & 181 \\
\hline 9. & Total cholesterol (mg/dL) & 162.26 & 32.54 \\
\hline 10. & HDL (mg/dL) & 29.66 & 89.166 \\
\hline 11. & LDL (mg/dL) & 103.66 & 28.83 \\
\hline 12. & VLDL (mg/dL) & 32.6 & 143.33 \\
\hline 13. & FBS (mg/dL) & 126.4 & Table 4: Comparison of Cases and controls Having Metabolic Syndrome \\
\hline \multicolumn{4}{|c|}{} \\
\hline
\end{tabular}

